Article

\title{
Is Fresh Produce in Tigray, Ethiopia a Potential Transmission Vehicle for Cryptosporidium and Giardia?
}

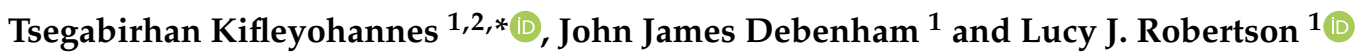 \\ 1 Institute of Paraclinical Sciences, Faculty of Veterinary Medicine, NMBU, 1430 Ås, Norway; \\ john.debenham@nmbu.no (J.J.D.); lucy.robertson@nmbu.no (L.J.R.) \\ 2 College of Veterinary Medicine, Mekelle University, Mekelle 2084, Ethiopia \\ * Correspondence: tsegabirhan.kyohannes.tesama@nmbu.no
}

check for updates

Citation: Kifleyohannes, T.;

Debenham, J.J.; Robertson, L.J. Is Fresh Produce in Tigray, Ethiopia a Potential Transmission Vehicle for Cryptosporidium and Giardia? Foods 2021, 10, 1979. https://doi.org/ $10.3390 /$ foods10091979

Academic Editor: Dario De Medici

Received: 16 July 2021

Accepted: 20 August 2021

Published: 25 August 2021

Publisher's Note: MDPI stays neutral with regard to jurisdictional claims in published maps and institutional affiliations.

Copyright: (c) 2021 by the authors. Licensee MDPI, Basel, Switzerland. This article is an open access article distributed under the terms and conditions of the Creative Commons Attribution (CC BY) license (https:// creativecommons.org/licenses/by/ $4.0 /)$.

\begin{abstract}
In rural Ethiopia, where people often share their homes with their livestock, infections of humans and animals with Cryptosporidium and Giardia are relatively common. One possible transmission route is consumption of contaminated fresh produce; this study investigated the occurrence of Cryptosporidium and Giardia in fresh produce in four districts of rural Tigray in Ethiopia. Fresh produce samples $(n=55)$ were analysed using standard laboratory procedures. Overall, $15 \%$ $(8 / 55)$ of samples were found to be contaminated. Although contamination levels were mostly low, a few samples had high numbers of Giardia cysts (up to around 70 cysts per $30 \mathrm{~g}$ sample). Molecular analyses were largely unsuccessful, but Giardia Assemblage A was identified in one sample. Contamination with these parasites was identified in two of the four districts, but, although a similar pattern has already been described for water contamination, this may be at least partially explained by sampling bias. Nevertheless, we speculate that access to clean water sources may be an important factor for reducing the occurrence of these pathogens. Given the public health and veterinary burden associated with both parasites, the factors which are of importance for their circulation in the communities and environments deserve further investigation.
\end{abstract}

Keywords: contamination; fruit; protozoa; vegetables; foodborne

\section{Introduction}

Foodborne parasitic diseases are an important public health concern globally [1] resulting in significant morbidity and mortality among susceptible populations [2]; the disease burden is particularly high in low and middle-income countries (LMIC) [2]. In the developed world, such as European countries, although the disease burden is lower, foodborne parasites are nevertheless also considered important, because of the challenges in monitoring, prevention, and control [3]; issues which are also relevant in LMIC.

According to WHO estimates of disease burden, foodborne parasitic diseases, excluding enteric protozoa, caused an estimated 23.2 million cases and 45,927 deaths in 2010, resulting in an estimated 6.64 million Disability Adjusted Life Years (DALYs) [2]. The same study showed that an additional 67.2 million cases, 5560 deaths, and 492,000 DALYs were due to foodborne enteric protozoa [2].

Fresh produce can be contaminated by enteric protozoan parasites, including Cryptosporidium and Giardia [4]. Contamination of fresh produce by parasites can occur preharvesting [5] during cultivation, via irrigation with contaminated water or sewage or the use of animal or human faeces as fertilizer. Contamination could also occur post-harvesting, by being washed with contaminated water or from handling by infected food-handlers $[4,6]$, or during transportation and storage [5].

The survival capabilities of Cryptosporidium oocysts and Giardia cysts in moist and refrigerated environments means that fresh produce is a suitable transmission vehicle [4]. Cryptosporidium oocysts are more robust than Giardia cysts, and oocysts can survive under less favourable storage conditions for more extended periods [7]. Cryptosporidium oocysts 
that have contaminated fresh produce during harvesting may be still infective at the marketplace where it is sold for human consumption. Although, Giardia cysts are more fragile and may not survive less-favourable environmental conditions [4], contamination of fresh produce, particularly post-harvesting, may still lead to foodborne transmission. The risk of infection by Cryptosporidium and Giardia from contaminated fruits like berries can be significantly decreased by simple washing before consumption [8]. However, due to the adherent nature of some parasites, washing does not completely remove all of them [7-9], and on some fresh produce rough surfaces, crevices or hairs may entrap parasites [10].

In developing countries, like Ethiopia, enteric protozoan infections, including Cryptosporidium and Giardia, are common [11]. Both parasites are well-known causes of gastro-intestinal illness worldwide [12]. Diarrhoea is the leading cause of mortality in children younger than 5 years in Ethiopia, accounting for more than 70,000 death annually, which $23 \%$ of all under-five deaths [13]. In addition, cryptosporidiosis is of particular concern in the immunocompromised [14], or those suffering from other health insults such as malnutrition [15]; given that both malnutrition and AIDS occur at higher rates in countries of Sub-Saharan Africa than in many other global regions this is of particular concern [16]. The proportion of this diarrhoea caused by zoonotic protozoan parasites is not well understood.

Investigations of parasitic contamination of vegetables and fruits collected from local markets have been conducted in various towns in Ethiopia [5,17-22]. All these studies used a washing procedure followed by microscopy (direct wet mount, iodine wet mount, and modified Ziehl-Neelsen staining) to identify parasitic contamination. In these studies, the proportion of fresh produce contaminated by Cryptosporidium oocysts has been reported to range from $4.7-12.8 \%$ and with Giardia cysts from $1.3-18.5 \%$ indicating relatively high occurrence of contamination [5,17-22]. One limitation of these studies was quantitative data on the level of contamination of the produce samples was not reported, nor was the recovery efficiencies of the methods used provided. Additionally, no attempt was made to speciate the identified parasites by molecular methods, which is necessary to determine their threat to public health. Thus, although several studies have indicated that contamination of fresh produce with Cryptosporidium and Giardia is relatively common in Ethiopia, the importance of this contamination to human health remains unknown.

In most of Ethiopia, fruits and vegetables are sold in open-air marketplaces and streets, and often this produce is eaten directly after purchase without washing (personal observation during sample collection). Fresh produce displayed for sale without washing has been reported to be more likely to be contaminated with parasites than washed fresh produce [5]. Fresh produce is usually carried to Ethiopian marketplaces by people or animals, or in animal-drawn carts; public transport or private vehicles are sometimes used. According to Alemu et al. 2020 [5], the fruits and vegetables transported to the marketplace by animals were more likely to be contaminated with parasites than fresh produce transported in motor vehicles [5].

As part of a larger One Health study on the epidemiology of cryptosporidiosis and giardiasis among humans and animals in rural areas of Tigray, Ethiopia, we investigated contamination of vegetables and fruits collected from farmers' backyards, irrigated farmlands, and open-air local markets at four locations. In the study areas, family labour was used for all the tasks, from land preparation to harvesting and transporting of the products to the market, organic manure (faeces of the animals) used to improve production.

Our aim was to determine the occurrence of Cryptosporidium and Giardia in fresh produce at four locations in Tigray, Ethiopia, to assess the species and genotypes of these parasites in order to provide information on transmission pathways and epidemiology, and to compare these data with the occurrence of the parasites in water samples previously reported from the four sampling districts. 


\section{Materials and Methods}

\subsection{Study Areas}

Between October 2018 and January 2019, samples of fresh produce (vegetables and fruits commonly eaten raw) were collected from local open-air markets, backyards of farmers, and irrigated farmlands from four selected districts of Tigray Region, Ethiopia, namely: Enderta (south-eastern zone of the region), Kilte Awulaelo (eastern zone), Hintalo Wejirat (south-eastern zone), and Raya Azebo (south zone).

Enderta (Location 1) is located at $13^{\circ} 14^{\prime} \mathrm{N}$ and $39^{\circ} 40^{\prime} \mathrm{E}$ with an altitude ranging from 1500 to 2300 metres above sea level (masl). The district covers a total area of $89,812 \mathrm{~km}^{2}$ of which 30,062 ha is cultivable land [23]. The total population of the district both in rural and urban areas is approximately 114,300 according to the 2015 population and housing census data [24]. Location 1 comprises of two agro-climatic zones. In the main zone, the mean annual maximum and minimum temperature is $24^{\circ} \mathrm{C}$ and $11^{\circ} \mathrm{C}$, respectively with an average annual rainfall of $601 \mathrm{~mm}$ [25]. A minor portion in the eastern and western parts has an elevation between 500 to 1500 masl, with an average temperature above $20^{\circ} \mathrm{C}$. The area is characterized by erratic rainfall and frequent droughts. The long rainy season is between June and September and the short rainy season is from March-May [25].

Hintalo Wejirat (Location 2) is at latitudes between $12^{\circ} 55^{\prime} \mathrm{N}$ and $13^{\circ} 20^{\prime} \mathrm{N}$ and longitudes $39^{\circ} 20^{\prime} \mathrm{E}$ and $39^{\circ} 55^{\prime} \mathrm{E}$ with an elevation area ranging from 1400 to 2850 masl. The district covers an area of 193,309 ha with an approximate total population of 153,500 [24,26]. The annual mean temperature in the area is $18{ }^{\circ} \mathrm{C}$. There are two rainy seasons in the district, the long rainy season from June-August and the short rainy season from March-April. Rainfall patterns can be erratic and in the north-west of the region average annual rainfall is up to $850 \mathrm{~mm}$, decreasing to $300-400 \mathrm{~mm}$ in the east [26].

Kilte Awulaelo (Location 3) is located between $13^{\circ} 45^{\prime} \mathrm{N}-14^{\circ} 00^{\prime} \mathrm{N}$ and $39^{\circ} 30^{\prime} \mathrm{E}-39^{\circ} 45^{\prime} \mathrm{E}$. The elevation ranges from 1980 to 2500 masl. The average daily air temperature ranges between $15^{\circ} \mathrm{C}$ and $30{ }^{\circ} \mathrm{C}$. The mean annual rainfall is $601 \mathrm{~mm}$. The district covers an area of 101,758 hectares, of which 21,620 hectares are farmlands $[27,28]$. The total population is approximately 99,700 [24].

Raya Azebo (Location 4) is located at $12^{\circ} 39^{\prime} \mathrm{N}$ latitude and $39^{\circ} 44^{\prime} \mathrm{E}$ longitude. The altitude ranges from 930 to 2300 masl. The area has two rainy seasons, with light rains between February to April period and heavy rains between July-September. The mean annual rainfall is $724 \mathrm{~mm}$, with mean daily maximum and minimum temperatures of $18^{\circ} \mathrm{C}$ and $14^{\circ} \mathrm{C}$, respectively for the western highlands and $23^{\circ} \mathrm{C}$ and $20^{\circ} \mathrm{C}$, respectively in the valleys [29]. The district covers an area of about 176,210 ha with a population of 135,870 [24].

The majority of households do not cultivate vegetables, rather relying on local markets to purchase fresh produce. In Tigray, for example, production of vegetables and fruits is reported in only $14 \%$ and $8 \%$ of households, respectively [30]. Historically, most cultivated land is used to grow various types of cereal crops, with only a small portion dedicated to vegetable production. This trend is changing, however, with an increase in vegetable production since 2014 [31]. According to Tigray agricultural marketing promotion agency, an estimated $90 \%$ of the overall vegetables grown in the region are sold in the local market and the remaining $10 \%$ are used at home for family consumption [31].

\subsection{Sample Collection}

Of the vegetables and fruits available for raw consumption in the regions studied, the most common ones are cabbage, lettuce, carrot, pepper, tomato, and guava. These are the fresh produce types included in our study. The samples were collected from the four districts which are subdivided into 'tabias' (villages). Twenty-four samples were analysed from Location 1 (4 tabias), five samples from Location 2 (1 tabia), twenty-one samples from Location 3 (4 tabias), and five samples from Location 4 (1 tabia) (Table 1). The number of samples collected from each district varied, being affected by the schedule of the local markets and relatively low vegetable production, such that fresh produce was not always available for sampling when we were visiting each location. The total numbers of samples 
analysed for each type of fresh produce were: cabbage (12), carrot (6), lettuce (13), pepper (9), tomato (9), and guava (6) (Table 1).

Study participants were interviewed regarding their sources of vegetables and fruits for consumption. Based on responses, samples of fresh produce were collected from the relevant sources. The participants reporting that they ate vegetables produced in their own backyards provided vegetable samples from this location. Some participants reported that their vegetables and fruits sources came from their own irrigated fields, and these samples were obtained from their fields. In all cases, the collected samples were put in a plastic bag, coded with date, district, and site of collection, and transported to the parasitology laboratory, College of Veterinary Medicine, Mekelle, Ethiopia.

Table 1. Sources of vegetables and fruits from the four locations.

\begin{tabular}{|c|c|c|c|c|}
\hline & Backyard & Fields & Market & Total \\
\hline \multicolumn{5}{|c|}{ Enderta (Location 1) } \\
\hline Cabbage & 0 & 5 & 2 & 7 \\
\hline Carrot & 0 & 0 & 2 & 2 \\
\hline Guava & 1 & 0 & 2 & 3 \\
\hline Lettuce & 0 & 2 & 3 & 5 \\
\hline Pepper & 1 & 0 & 3 & 4 \\
\hline Tomato & 0 & 0 & 3 & 3 \\
\hline Total & 2 & 7 & 15 & 24 \\
\hline \multicolumn{5}{|c|}{ Hintalo Wejirat (Location 2) } \\
\hline Cabbage & 0 & 0 & 1 & 1 \\
\hline Carrot & 0 & 0 & 1 & 1 \\
\hline Guava & 0 & 0 & 0 & 0 \\
\hline Lettuce & 0 & 0 & 1 & 1 \\
\hline Pepper & 0 & 0 & 1 & 1 \\
\hline Tomato & 0 & 0 & 1 & 1 \\
\hline Total & 0 & 0 & 5 & 5 \\
\hline \multicolumn{5}{|c|}{ Kilte Awulaelo (Location 3) } \\
\hline Cabbage & 0 & 1 & 2 & 3 \\
\hline Carrot & 0 & 0 & 2 & 2 \\
\hline Guava & 0 & 2 & 1 & 3 \\
\hline Lettuce & 2 & 2 & 2 & 6 \\
\hline Pepper & 1 & 0 & 2 & 3 \\
\hline Tomato & 0 & 2 & 2 & 4 \\
\hline Total & 3 & 7 & 11 & 21 \\
\hline \multicolumn{5}{|c|}{ Raya Azebo (Location 4) } \\
\hline Cabbage & 0 & 0 & 1 & 1 \\
\hline Carrot & 0 & 0 & 1 & 1 \\
\hline Guava & 0 & 0 & 0 & 0 \\
\hline Lettuce & 0 & 0 & 1 & 1 \\
\hline Pepper & 0 & 0 & 1 & 1 \\
\hline Tomato & 0 & 0 & 1 & 1 \\
\hline Total & 0 & 0 & 5 & 5 \\
\hline Grand total & 5 & 14 & 36 & 55 \\
\hline
\end{tabular}

\subsection{Preparation of the Sample for Analysis}

The samples were refrigerated at $4{ }^{\circ} \mathrm{C}$ for a maximum of $24 \mathrm{~h}$ at the parasitology laboratory and processed on the following day. For leafy vegetables (lettuce and cabbage) and peppers, $30 \mathrm{~g}$ were weighed into stomacher bags (Seward BA6041/STRfilter bag), $200 \mathrm{~mL}$ of $1 \mathrm{M}$ glycine buffer was added to immerse the sample, and the samples were processed by stomacher/paddle blender for one minute. For carrots, tomatoes, and guava one or two were selected on the basis of their size and put into filtered stomacher bags and washed for $5 \mathrm{~min}$ by hand in $200 \mathrm{~mL}$ of $1 \mathrm{M}$ glycine buffer [4].

The eluate was transferred into five $50 \mathrm{~mL}$ centrifuge tubes, the bag washed with distilled water, and the wash water transferred to the tubes. The tubes were transported 
to Ayder Referral Hospital, Department of Microbiology, Mekelle on the same day, where they were centrifuged for $10 \mathrm{~min}$ at 1550 relative centrifugal force. Following aspiration of the supernatant, the pellets were vortexed and combined in a single tube per sample and refrigerated at $4{ }^{\circ} \mathrm{C}$ before being transported to Norway for further analysis.

\subsection{Immunomagnetic Separation (IMS)}

IMS was performed using Dynabeads GC-combo kit for isolation of Cryptosporidium oocysts and Giardia cysts. Although 16 samples from Location 1 district were processed according to the ISO 18744 [32] protocol, all other samples were processed following a reduced-cost protocol that is based on this standard, but uses fewer beads $(20 \mu \mathrm{L}$ of each bead type), and modified buffers (as well as the buffers provided with the kit, PBS-Tween and SurModics StabliZyme AP buffer); the efficiency of the modified method is comparable to that of the ISO Method (30-50\%) but is considerably cheaper due to the reduction in use of reagents [33].

\subsection{Detection of Cryptosporidium Oocysts and Giardia Cysts Using Immunofluorescent Antibody Staining (IFAT)}

Single-well slides of air-dried sample concentrates were fixed with methanol and stained with fluorescein isothiocyanate (FITC)-conjugated monoclonal antibodies (mABs) against Cryptosporidium oocyst walls and Giardia cyst walls (Aqua-glo ${ }^{\mathrm{TM}}$, Waterborne ${ }^{\mathrm{TM}}$ Inc., New Orleans, LA, USA) and 4',6' diamidino-2-phenylindole (DAPI) was used to stain the DNA in the nuclei of these organisms. Samples were mounted with M101 No-Fade Mounting Medium then each slide was covered by a glass coverslip and viewed immediately.

A Leica DCMB fluorescence microscope equipped with Nomarski differential interference contrast (DIC) optics was used for examination of the slides. A blue filter block (480 nm-excitation, $520 \mathrm{~nm}$-emission) was used to visualize FITC conjugated mABS labelled cysts and oocysts and a UV filter block (350 nm excitation, $450 \mathrm{~nm}$ emission) was used to visualize the presence or absence of DAPI-stained sporozoite nuclei. All observations were at $200 \times$ or $400 \times$ magnification.

The entire well of the stained slides was examined for the presence or absence of Cryptosporidium oocysts and Giardia cysts; preliminary identification was based on reactivity with the monoclonal antibody and appropriate shape and size. Ovoid or spherical objects with brilliant apple-green fluorescence of the appropriate size and shape were examined under the UV filter to determine the presence of nuclei, both to support identification (if present) and for assessing the sample suitability for further investigation by molecular methods. The number of Cryptosporidium oocysts and Giardia cysts observed per sample was recorded.

\subsection{Recovery Efficiency of the Method}

The recovery efficiencies of both the methods used were estimated using spiked samples in which known numbers of flow cytometry-sorted oocysts and cysts (AccuSpike ${ }^{\mathrm{TM}}$-IR; Waterborne Inc., New Orleans, LA, USA and EasySeed ${ }^{\mathrm{TM}}$, TCS Biosciences Ltd., Botolph Claydon, UK) were spiked onto $30 \mathrm{~g}$ lettuce and dried at room temperature for $2 \mathrm{~h}$ before analysis as described. Recovery efficiencies were estimated to be approximately $30 \%$ for Cryptosporidium and 55\% for Giardia, regardless of whether the ISO 18744 [32] protocol or reduced-cost method was used [33]. This is within the range considered acceptable using the ISO or US EPA methods for analysis of water samples.

\subsection{DNA Extraction}

DNA extraction was conducted on positive samples using DNeasy PowerSoil Kit (Qiagen, Oslo, Norway) protocol, with some modifications. The fresh produce sample post IMS $(250 \mu \mathrm{L})$ and $60 \mu \mathrm{L}$ of the lysis solution (solution C1) were added to the PowerBead Tubes and vortexed together to mix. This was then subjected to bead beating to release the DNA by breaking the oo(cyst) walls using a FastPrep-24 5G (MP Biomedicals) in two cycles of 4 metre/s for $60 \mathrm{~s}$ with a $45 \mathrm{~s}$ pause between the cycles. In the end, the DNA 
was eluted in $40 \mu \mathrm{L}$ of the elution solution (solution C6) and stored at $-20{ }^{\circ} \mathrm{C}$. A recent study by Temesgen et al., 2021 [8] reported that the bead-beating approach is effective for obtaining the DNA of Cryptosporidium and Giardia from artificially contaminated berries.

\subsection{Polymerase Chain Reaction and Sequencing}

For Giardia investigation, PCR targeting the glutamate dehydrogenase gene, betagiardin gene, and SSU gene were conducted according to published protocols [34,35]. For Cryptosporidium, PCR targeting the SSU-rRNA gene was conducted [35]. Details of primers and cycling conditions are listed in the Supplementary File S1. Negative and positive controls were included in each PCR run.

Reactions were carried out in a total volume of $25 \mu \mathrm{L}$ that included $2 \mu \mathrm{L}$ of template DNA, $0.4 \mu \mathrm{M}$ of each primer and $12.5 \mu \mathrm{L}$ of DreamTaq PCR Master Mix (2X) (Thermo Fisher Scientific, Oslo, Norway). Bovine serum albumin (BSA) $0.2 \mu \mathrm{L}$ of $(20 \mathrm{mg} / \mathrm{mL}$ ) was used in the reaction targeting the beta giardin and GDH genes.

The PCR products were examined following separation on a $2 \%$ agarose gel, stained with SYBR Safe DNA gel stain and visualized under UV illumination. A ready-to-use DNA ladder (Thermo Scientific, Oslo, Norway) of $100 \mathrm{bp}$ was used for fragment size determination.

Purification of the positive products was carried out using ExoSAP-IT PCR product clean-up reagent (Thermofisher Scientific, Oslo, Norway) and sent to a commercial company (EUROFINS GENOMICS, Ebersberg bei München, Germany) for sequencing in both directions. Sequences were checked using Geneious prime software and compared with sequences in GenBank using NCBI BLAST.

\subsection{Statistics and Data Handling}

Results were collected in a database in Excel. Data analysis was made using simple descriptive statistics and frequency using STATA version 15. Fisher's exact test was used to determine associations with sample location and detection of parasites and also between sources of samples and detection of parasites.

\section{Results}

\subsection{Occurrence of Cryptosporidium and Giardia on Vegetables and Fruits}

Out of 55 fresh produce samples processed, 8 (15\%) were found to be contaminated with Cryptosporidium oocysts and/or Giardia cysts. DAPI staining was not observed in any of the oocysts or cysts, indicating that the oocysts or cysts had ruptured and there was no longer nuclear material within the oocysts or cysts. Of these 8 samples, 2 were contaminated with Cryptosporidium only, 5 were contaminated with Giardia only, and 1 was contaminated with both Giardia and Cryptosporidium. All 8 positive samples were from Location 1 and Location 3 districts, which were also the districts from which most samples were collected.

The contamination rate of different types of fresh produce is depicted in Figure 1 . The contamination rate for cabbage was $3 / 12(25 \%)$, lettuce $2 / 13(15 \%)$, guava $2 / 6(33 \%)$ and pepper $1 / 9(11 \%)$. Contamination with these parasites was not detected on either carrot or tomato samples.

The number of contaminating oo(cysts) per sample of vegetable and fruits are described in Table 2. The degree of contamination was low for both parasites, with the exception of one cabbage sample where 71 Giardia cysts were counted and one lettuce sample where 28 Giardia cysts were counted; all other positive samples had fewer than 20 oo(cysts).

Of the positive samples, 1 (Giardia positive) was obtained from a backyard (of 5 total backyard samples), 3 from farmers' fields (1 Cryptosporidium positive, 1 Giardia positive, and 1 with both parasites of 14 field samples), and 4 from markets (2 Giardia positive and 2 Cryptosporidium positive of 36 market samples). No source was more or less likely to be contaminated with these parasites than another. 


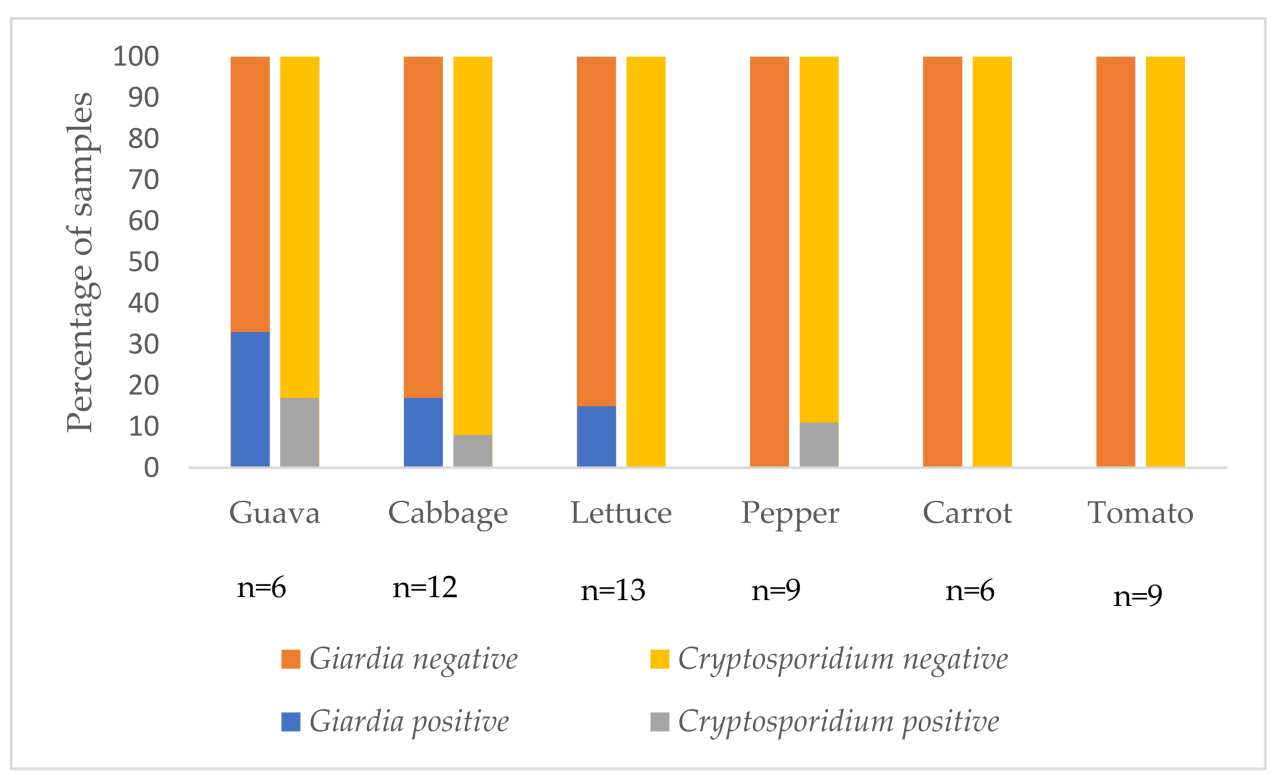

Figure 1. Proportion of Giardia and Cryptosporidium contaminated fresh produce samples.

Table 2. Intensity of contamination of fresh produce with Cryptosporidium oocysts and Giardia cysts.

\begin{tabular}{cccc}
\hline Sampling Area & $\begin{array}{c}\text { Type of Fresh } \\
\text { Produce }\end{array}$ & $\begin{array}{c}\text { Number of } \\
\text { Cryptosporidium } \\
\text { Oocysts Counted }\end{array}$ & $\begin{array}{c}\text { Number of Giardia } \\
\text { Cysts Counted }\end{array}$ \\
\hline \multirow{2}{*}{ Location 1} & Pepper & 2 & 0 \\
& Lettuce & 0 & 3 \\
& Cabbage & 0 & 71 \\
Location 3 & Cabbage & 0 & 3 \\
& Lettuce & 0 & 28 \\
& Guava & 0 & 1 \\
& Guava & 3 & 0 \\
\hline Total positive samples & Cabbage & 2 & 6 \\
\hline
\end{tabular}

\subsection{Genotyping of Cryptosporidium and Giardia}

DNA was isolated from the three samples with the highest number of Giardia cysts (71, 28, and 11 cysts), in the latter of which Cryptosporidium oocysts were also detected, and also from the two other Cryptosporidium positive samples.

PCR resulted in amplification at the Giardia SSU gene from the sample containing 28 cysts (lettuce sample from Location 3, Kilte Awulaelo). DNA sequencing of this PCR product was successful, and revealed it to be Assemblage A, with $99 \%$ similarity to sequences at GenBank Accession numbers MH047247.1 and MH047246.1. All other PCR attempts for the other Giardia and Cryptosporidium positive samples were unsuccessful despite multiple attempts at several genes.

\subsection{Comparison between Occurrence of Positive Samples in Fresh Produce and Water in the} Four Districts

In our previous article [36], contamination of drinking water with Cryptosporidium and Giardia appeared to occur frequently in Locations 1 (Enderta) and 3 (Kilte Awulaelo). These are also the two locations where contamination was found in fresh produce (Table 3). In addition, the fresh produce sample with 71 Giardia cysts came from Location 1, and a high count of Giardia cysts ( 22 cysts in $10 \mathrm{~L}$ ) was also observed in one water sample from this location [36]. 
Table 3. Occurrence of contamination of fresh produce with Cryptosporidium and Giardia oo(cysts) compared with water in the same locations.

\begin{tabular}{ccccc}
\hline & \multicolumn{3}{c}{ Proportion (\%) of Samples Positive } \\
\cline { 2 - 5 } & \multicolumn{2}{c}{ Fresh Produce Samples } & \multicolumn{2}{c}{ Water Samples } \\
\cline { 2 - 5 } & Cryptosporidium & Giardia & Cryptosporidium & Giardia \\
\hline Location 1 & $4 \%(1 / 24)$ & $13 \%(3 / 24)$ & $7 \%(1 / 15)$ & $40 \%(6 / 15)$ \\
\hline Location 2 & $\mathrm{ND}^{1}(0 / 5)$ & $\mathrm{ND}(0 / 5)$ & $\mathrm{ND}(0 / 7)$ & $\mathrm{ND}(0 / 7)$ \\
\hline Location 3 & $10 \%(2 / 21)$ & $14 \%(3 / 21)$ & $8 \%(1 / 13)$ & $\mathrm{ND}(0 / 13)$ \\
\hline Location 4 & $\mathrm{ND}(0 / 5)$ & $\mathrm{ND}(0 / 5)$ & $\mathrm{ND}(0 / 2)$ & $\mathrm{ND}(0 / 2)$ \\
\hline
\end{tabular}

${ }^{1}$ ND-Not detected.

\section{Discussion}

This study investigated the extent of contamination of fresh produce with the protozoan parasites Cryptosporidium and Giardia in four districts of rural Tigray, northern Ethiopia. The most important finding from this study is that contamination of fresh produce with these parasites occurs relatively frequently in this area, with 8 out of 55 samples $(15 \%)$ positive for Cryptosporidium and/or Giardia. Contamination was only found in two districts, Location 1 and Location 3, with a district-specific occurrence of $4 / 24(17 \%)$ and 4/21 (19\%), respectively. However, it should be noted that considerably more samples were analysed from these districts (45 samples in total from Locations 1 and 3, and 10 samples in total from Locations 2 and 4). This sampling bias means that we cannot reach a conclusion on whether the contamination risk was higher in Locations 1 and 3 than in Locations 2 and 4.

Other reports from Ethiopia on contamination of fresh produce have produced similar results regarding the proportion of contaminated fresh produce. For example, Alemu et al., (2020) [5] reported $4.9 \%$ and 10.2\% occurrence of Cryptosporidium spp. and Giardia contamination, respectively, from vegetable and fruit samples collected from local markets in Bahirdar city, northwest Ethiopia. Similarly, Bekele et al., 2017 [20] reported a prevalence of Cryptosporidium spp. and Giardia of $4.7 \%$ and 10\%, respectively, from vegetables and fruits collected from local markets in Arba Minch town, southern Ethiopia. Moreover, Endale et al., 2018 [37] reported 7.7\% and 9.3\% prevalence of Cryptosporidium spp. and Giardia, respectively, from vegetables and fruits collected from local markets in Dire Dawa, Eastern Ethiopia. Furthermore, Tefera et al., 2014 [22], reported contamination with Cryptosporidium spp. (12.8\%) and Giardia (7.5\%) from fruits and vegetables collected from selected local markets of Jimma town, Southwest Ethiopia. Nevertheless, the only similar study that we could find from Tigray reported a higher occurrence than we found with $7.3 \%$ and $18.5 \%$ occurrence of Cryptosporidium and Giardia on fresh produce from markets in the town of Aksum [19]. Discrepancies between our data and others from Ethiopia could be due to real differences in the occurrence of these parasites in different geographical locations but could also reflect differences in the laboratory analysis method. As IFAT is both more sensitive and more specific than traditional microscopy methods used in these other studies, both false-negative and false-positive results should be lower.

As previously noted, none of these other studies from Ethiopia quantified the extent of contamination. Although in our study the number of parasites detected per sample was usually low (mostly fewer than 5 (oo)cysts per $30 \mathrm{~g}$ sample), a few of the samples were quite heavily contaminated, with one sample harbouring over 70 Giardia cysts. Reports from other parts of the world also generally indicate low numbers of parasites among contaminated fresh produce. For example, a study from Norway reported 1-8 Cryptosporidium oocysts or Giardia cysts in $100 \mathrm{~g}$ samples of various types of fruits and vegetables [38]. More relevant to this current investigation is a study of vegetables from retail in India, where among positive samples of fresh produce obtained from street vendors, parasite (Cryptosporidium and Giardia) counts were usually below 10 per $30 \mathrm{~g}$ sample [4]. However, as in our study, some samples had very high counts [4], although, unlike in our study, this tended to be for Cryptosporidium 
oocysts rather than Giardia cysts. Another variable of interest is the type of fresh produce examined. In this study we analysed samples of vegetables commonly eaten raw (cabbage, carrot, lettuce, pepper, tomato) and guava. Although only a few guava samples were analysed, it was found to be the fresh produce most likely to be contaminated, with Cryptosporidium in 33\% (2/6) and Giardia in 17\% (1/6) of guava samples, followed by cabbage, lettuce, and pepper. Neither Cryptosporidium nor Giardia were detected on tomatoes and carrots. The reason for this may reflect factors associated with cultivation (carrots are below the surface of the soil and therefore less likely to be directly contaminated) or other factors, such as transport. As tomatoes are more likely to be damaged than the other fresh produces, they may be transported in containers and are therefore less likely to be contaminated during transport. Cabbage and lettuce may be more likely to be contaminated due to their high surface area, and their rough surfaces $[5,7,20]$. The higher contamination of guava is interesting, as they are on trees and thus unlikely to be contaminated in the field; thus, contamination during or post-harvest seems most likely.

None of the other studies from Ethiopia have investigated the species (Cryptosporidium) or genotype (both Cryptosporidium and Giardia) contaminating fresh produce. This information may provide clues on the source of contamination, and indicate the potential public health significance. Although we were only able to obtain data from one sample of Giardia, the finding of Assemblage A, which is known to infect humans and animals, opens for the possibility of multiple different transmission routes leading to contaminated produce, including zoonotic transmission.

Water analysed from all four study districts for these parasites also indicated water contamination at Locations 1 and 3 (Enderta and Kilte Awulaelo), but not at the other two locations [36]. However, as for the fresh produce samples, relatively few water samples were analysed from Locations 2 and 4 . At Locations 1 and 3, there were more water sources available for sampling, whereas at Locations 2 and 4 several of the water sources were out of order (e.g., hand pumps) and at Location 4 there was a main common water source which limited sample collection. Although this sampling bias for both water and fresh produce could have influenced our results, it is also possible that these parasites are circulating more in the environment in some locations than others, and it would be of interest to examine this in greater detail. One possible explanation for the relative absence of environmental contamination at location 4 (Raya Azebo-Mechare tabia) is that the main water source was in-house tap water. Such a water supply is less likely to be contaminated by people and animals, and less likely to spread contamination to fresh produce or act as a transmission vehicle to those drinking it. Water supply has previously been shown to be a risk factor for diarrhoeal disease [39].

As with many studies, there are some important limitations in this study. The total number of fresh produce samples that we analysed was relatively low (55) compared to other studies, including those from Ethiopia where reported sample sizes were between 108 to $384[5,17-22,37]$. As our fresh produce samples were collected along with other samples, we were limited by resources. In addition, most of our study participants bought fresh produce from the market, which occurred only once per week, so opportunities for sample collection were restricted. In addition, we had challenges in our molecular analyses, and this reflects the relatively few positive samples, low concentrations of parasites, and a lack of nucleated parasites (as demonstrated by inclusion of DAPI) in those samples that were positive. Although DAPI staining was absent in the parasites detected on all positive vegetables, we speculated that the DNA may be in the suspension following elution of the samples and therefore conducted the molecular analyses. The nuclei could have been lost during transport, storage, and processing, particularly from Giardia cysts that are not as robust as Cryptosporidium oocysts [7]. Our molecular result from one of Giardia positive sample corroborates this suggestion, as DNA amplification was possible. It is not possible to determine whether the parasites contaminating the fresh produce were viable or infectious at the time of sample collection, and therefore presenting a public health risk to consumers. The lack of oo(cyst) nuclei at detection suggests that the parasites were 
non-infective. However, it is possible that damage to the oo(cyst)s occurred after sample collection, such as during transport, storage, or processing, and were indeed infective at the time of sampling.

In conclusion, our study found that contamination of fresh produce with Cryptosporidium oocysts and Giardia cysts was relatively common in Tigray region. Despite the fact that contamination was only detected in two of the four districts in the study, this could reflect sampling bias rather than a lack of contamination at Locations 2 and 4. Although contamination levels in positive samples were generally low, a few samples were more heavily contaminated with Giardia cysts. Similar results have already been reported regarding contamination of water supply, with the same two districts apparently having cleaner water. Although our data may suggest certain factors in specific locations may contribute to the circulation of these parasites within the environment, sampling bias also has a role. Given the public health and veterinary burden associated with both parasites, trying to pinpoint the factors of importance in reducing the circulation of these parasites in the communities and environments deserves further investigation.

Supplementary Materials: The following are available online at https:/ / www.mdpi.com/article/10 .3390 / foods10091979/s1, Table S1: PCR conditions and primers. Supplementary File S1.

Author Contributions: Conceptualization, T.K., L.J.R. and J.J.D.; methodology, T.K., J.J.D. and L.J.R.; validation, L.J.R.; formal analysis, T.K. and L.J.R.; investigation, T.K.; data curation, T.K.; writingoriginal draft preparation, T.K.; writing—review and editing, T.K., J.J.D. and L.J.R.; visualization, T.K. and L.J.R.; supervision, L.J.R. and J.J.D.; project administration L.J.R.; funding acquisition, T.K. and L.J.R. All authors have read and agreed to the published version of the manuscript.

Funding: This study was funded by the Norwegian Ministry of Foreign Affairs through the NMBUMU Institutional Collaboration Phase IV, Improved Livelihood of the Rural Communities in the Arid Highlands of Northern Ethiopia.

Acknowledgments: We are very grateful to all participants involved in this study. We are also grateful for project support from Kristoffer Tysnes and Ane C. W. Nødtvedt both at NMBU, as well as Getachew Terefe from College of Veterinary Medicine and Agriculture at Addis Ababa University for his continued support and supervision throughout the project and helpful comments on the manuscript. In addition, we are grateful to Kjersti Selstad Utaaker for assistance with the analytical methodology. We would also like to thank Habtamu Taddele, Yohannes Hagos, Tadesse Teferi, and Haftay Abraha for their support and assistance during sample collection.

Conflicts of Interest: The authors declare no conflict of interest. The funders had no role in the design of the study; in the collection, analyses, or interpretation of data; in the writing of the manuscript, or in the decision to publish the results.

\section{References}

1. Robertson, L.J. Parasites in Food: From a Neglected Position to an Emerging Issue. Adv. Food Nutr. Res. 2018, 86, 71-113. [CrossRef] [PubMed]

2. Torgerson, P.R.; Devleesschauwer, B.; Praet, N.; Speybroeck, N.; Willingham, A.L.; Kasuga, F.; Rokni, M.B.; Zhou, X.N.; Fèvre, E.M.; Sripa, B.; et al. World Health Organization Estimates of the Global and Regional Disease Burden of 11 Foodborne Parasitic Diseases, 2010: A Data Synthesis. PLoS Med. 2015, 12, e1001920. [CrossRef] [PubMed]

3. Koutsoumanis, K.; Allende, A.; Alvarez-Ordóñez, A.; Bolton, D.; Bover-Cid, S.; Chemaly, M.; Davies, R.; De Cesare, A.; Herman, L.; Hilbert, F.; et al. Public health risks associated with food-borne parasites. EFSA J. 2018, 16, e05495. [CrossRef] [PubMed]

4. Utaaker, K.S.; Kumar, A.; Joshi, H.; Chaudhary, S.; Robertson, L.J. Checking the detail in retail: Occurrence of Cryptosporidium and Giardia on vegetables sold across different counters in Chandigarh, India. Int. J. Food Microbiol. 2017, 263, 1-8. [CrossRef] [PubMed]

5. Alemu, G.; Nega, M.; Alemu, M. Parasitic Contamination of Fruits and Vegetables Collected from Local Markets of Bahir Dar City, Northwest Ethiopia. Res. Rep. Trop. Med. 2020, 11, 17-25. [CrossRef]

6. Doyle, M.E. Foodborne Parasites, A Review of the Scientific Literature Review. FRI BRIEFINGS: Foodborne Parasites. University of Wisconsin-Madison. 2003. Available online: https://fri.wisc.edu/files/Briefs_File/parasites.pdf (accessed on 2 February 2021).

7. Utaaker, K.S.; Skjerve, E.; Robertson, L.J. Keeping it cool: Survival of Giardia cysts and Cryptosporidium oocysts on lettuce leaves. Int. J. Food Microbiol. 2017, 255, 51-57. [CrossRef] 
8. Temesgen, T.T.; Robertson, L.J.; Stigum, V.M.; Tysnes, K.R. Removal of parasite transmission stages from berries using washing procedures suitable for consumers. Foods 2021, 10, 481. [CrossRef]

9. MacArisin, D.; Santín, M.; Bauchan, G.; Fayer, R. Infectivity of Cryptosporidium parvum oocysts after storage of experimentally contaminated apples. J. Food Prot. 2010, 73, 1824-1829. [CrossRef]

10. Ismail, Y. Prevalence of parasitic contamination in salad vegetables collected from supermarkets and street vendors in Amman and Baqa'a-Jordan. Pol. J. Microbiol. 2016, 65, 201-207. [CrossRef]

11. Tegen, D.; Damtie, D.; Hailegebriel, T. Prevalence and Associated Risk Factors of Human Intestinal Protozoan Parasitic Infections in Ethiopia: A Systematic Review and Meta-Analysis. J. Parasitol. Res. 2020, 2020, 8884064. [CrossRef]

12. Cacciò, S.M.; Thompson, R.C.A.; McLauchlin, J.; Smith, H.V. Unravelling Cryptosporidium and Giardia epidemiology. Trends Parasitol. 2005, 21, 430-437. [CrossRef]

13. United Nations International Children's Emergency Fund (UNICEF). Ethiopia Water, Sanitation and Hygiene (WASH) | UNICEF Ethiopia 2018. Available online: https:/ / www.unicef.org/ethiopia/water-sanitation-and-hygiene-wash (accessed on 2 February 2021).

14. Wang, H.; Qi, M.; Zhang, K.; Li, J.; Huang, J.; Ning, C.; Zhang, L. Prevalence and genotyping of Giardia duodenalis isolated from sheep in Henan Province, central China. Infect. Genet. Evol. 2016, 39, 330-335. [CrossRef]

15. Korpe, P.S.; Valencia, C.; Haque, R.; Mahfuz, M.; McGrath, M.; Houpt, E.; Kosek, M.; McCormick, B.J.J.; Penataro Yori, P.; Babji, S.; et al. Epidemiology and Risk Factors for Cryptosporidiosis in Children from 8 Low-income Sites: Results from the MAL-ED Study. Clin. Infect. Dis. 2018, 67, 1660-1669. [CrossRef]

16. Odugbesan, J.A.; Rjoub, H. Evaluating HIV/Aids prevalence and sustainable development in sub-Saharan Africa: The role of health expenditure. Afr. Health Sci. 2020, 20, 568. [CrossRef]

17. Alemu, G.; Mama, M.; Misker, D.; Haftu, D. Parasitic contamination of vegetables marketed in Arba Minch town, southern Ethiopia. BMC Infect. Dis. 2019, 19, 410. [CrossRef]

18. Aksum, E. Parasitological Contamination of Fresh Vegetables and Its Prevalence in Dessie Town, Northeast Ethiopia. Res. Net. 2018, 8, 27-33. [CrossRef]

19. Kiros, G.; Girmay, T.G. Parasitic Contamination of Fresh Vegetables in Open-Air Markets of Aksum, Ethiopia. Research Square, Preprint. 2020, pp. 1-10. Available online: https:/ / doi.org/10.21203/rs.3.rs-70164/v1 (accessed on 17 March 2021).

20. Bekele, F.; Tefera, T.; Biresaw, G.; Yohannes, T. Parasitic contamination of raw vegetables and fruits collected from selected local markets in Arba Minch town, Southern Ethiopia. Infect. Dis. Poverty 2017, 6, 1-7. [CrossRef]

21. Bekele, F.; Shumbej, T. Fruit and vegetable contamination with medically important helminths and protozoans in Tarcha town, Dawuro zone, South West Ethiopia. Res. Rep. Trop. Med. 2019, 10, 19-23. [CrossRef]

22. Tefera, T.; Biruksew, A.; Mekonnen, Z.; Eshetu, T. Parasitic Contamination of Fruits and Vegetables Collected from Selected Local Markets of Jimma Town, Southwest Ethiopia. Int. Sch. Res. Not. 2014, 2014, 382715. [CrossRef]

23. Tekle, L.; Hadush, H.; Hadas, B. Evaluation of frontline demonstration of herbicide (Pyroxsulam) for weed control in bread wheat in Tigray, Northern Ethiopia. J. Agric. Ext. Rural Dev. 2018, 10, 20-27. [CrossRef]

24. CSA 2007 Population and Housing Census Data. 2007. Available online: https://www.statsethiopia.gov.et/census-2007-2/ (accessed on 5 January 2019).

25. Yibrah, M.; Korecha, D.; Dandesa, T. Characterization of Rainfall and Temperature Variability to Guide Wheat (Triticum aestivum) and Barley (Horduem vulgare) Production in Enderta District, Southeastern Tigray, Ethiopia. Int. J. Res. Environ. Sci. 2018, 4 , 2454-9444. Available online: www.arcjournals.org (accessed on 8 February 2021). [CrossRef]

26. Davies, J.; Merrin, P.D. Project Report on Visit to Ethiopia to Rapidly Assess Groundwater Development Issues in the Hintalo Wajerat Woreda. 2000. Available online: http:/ / nora.nerc.ac.uk/id/eprint/506810/1/WC00016.pdf (accessed on 8 February 2021).

27. Teklay, A.; Abera, B.; Giday, M. An ethnobotanical study of medicinal plants used in Kilte Awulaelo district, Tigray region of Ethiopia. J. Ethnobiol. Ethnomed. 2013, 9, 1. [CrossRef]

28. Hagos, L.G. The Role of Household Ponds on the Expansion of Homegardens in Tigray, Ethiopia. Master's Thesis, Mekelle University, Mekelle, Ethiopia, 2005. Available online: https://www.musgroup.net/node/383 (accessed on 7 February 2021).

29. Tesfay, G.; Gebresamuel, G.; Gebretsadik, A.; Gebrelibanos, A.; Gebremeskel, Y.; Hagos, T. Participatory Rural Appraisal Report: Raya-Azebo Woreda, Tigray Region. Cascape Working Paper 2.6.3. 2014. Available online: https://docplayer.net/155239385Participatory-rural-appraisal-report-ofla-woreda-tigray-region.html (accessed on 1 March 2021).

30. Hunde, N.F. Opportunity, Problems and Production Status of Vegetables in Ethiopia: A Review. J. Plant Sci. Res. 2017, 4, 1-14.

31. Kahsay, G.N. Identifying Challenges and Opportunities on the Development of Sustainable Vegetable Agro-Industries in the National Regional State of Tigray. 2011. Available online: https://opendocs.ids.ac.uk/opendocs/handle/20.500.12413/4541 (accessed on 1 March 2021).

32. ISO, 2016.ISO 18744:2016. In Microbiology of the Food Chain-Detection and Enumeration of Cryptosporidium and Giardia in Fresh Leafy Green Vegetables and Berry Fruits; ISO Copyright Office: Geneva, Switzerland, 2016. Available online: https://www.iso.org/ standard/63252.html (accessed on 1 March 2021).

33. Utaaker, K.S.; Huang, Q.; Robertson, L.J. A reduced-cost approach for analyzing fresh produce for contamination with Cryptosporidium oocysts and/or Giardia cysts. Food Res. Int. 2015, 77, 326-332. [CrossRef]

34. Utaaker, K.S.; Biology, I. Intestinal Protozoan Parasites in Northern India-Investigations on Transmission Routes. Ph.D. Thesis, Norwegian University of Life Sciences (NMBU), Ås, Norway, 2018. 
35. Gharieb, R.M.A.; Bowman, D.D.; Liotta, J.L.; Xiao, L. Isolation, genotyping and subtyping of single Cryptosporidium oocysts from calves with special reference to zoonotic significance. Vet. Parasitol. 2019, 271, 80-86. [CrossRef]

36. Kifleyohannes, T.; Robertson, L.J. Preliminary insights regarding water as a transmission vehicle for Cryptosporidium and Giardia in Tigray, Ethiopia. Food Waterborne Parasitol. 2020, 19, e00073. [CrossRef]

37. Endale, A.; Tafa, B.; Bekele, D.; Tesfaye, F. Detection of medically important parasites in fruits and vegetables collected from local markets in Dire Dawa, Eastern Ethiopia. Glob. J. Med. Res. 2018, 18, 29-36.

38. Robertson, L.J.; Gjerde, B. Occurrence of parasites on fruits and vegetables in Norway. J. Food Prot. 2001, 64, 1793-1798. [CrossRef]

39. Wolf, J.; Hunter, P.R.; Freeman, M.C.; Cumming, O.; Clasen, T.; Bartram, J.; Higgins, J.P.T.; Johnston, R.; Medlicott, K.; Boisson, S.; et al. Impact of drinking water, sanitation and handwashing with soap on childhood diarrhoeal disease: Updated meta-analysis and meta-regression. Trop. Med. Int. Health 2018, 23, 508-525. [CrossRef] 